\title{
Spectroscopic Substantiation for the Identification of Degradants by Q-TOF Micromass (ESI-MS) in Bisoprolol Fumarate with an Inventive Validation Approach for Stability Indicating HPLC Method
}

\author{
Swati Pandey, Ravindra Pandey², Shiv Shankar Shukla,,* \\ ${ }^{1}$ Department of Pharmaceutical Analysis and Quality Assurance, Columbia Institute of Pharmacy, Raipur, Chhattisgarh, INDIA. \\ ${ }^{2}$ Department of Pharmacognosy, Columbia Institute of Pharmacy, Raipur, Chhattisgarh, INDIA.
}

\begin{abstract}
Background: Stability studies, stress testing of drug substances and finished drug product is obligatory due to the guidelines by the International Council for Harmonisation of Technical Requirements for Pharmaceuticals for Human Use (ICH) and other Regulatory Authorities. Materials and Methods: In the present work the selective Beta-1 receptor blocker, Bisoprolol fumarate was subjected to the forced degradation studies which includes hydrolysis (acidic, basic and neutral), oxidative, photolytic and thermal degradation. The drug was stable under light and basic and neutral medium. Results: The major findings in the presented work are the degradation products formed in the course of thermal degradation. The complete thermal degradation products were identified by High Performance Liquid Chromatography, Quadrupole-Time of Flight micromass (Electronspray lonization-Mass Spectroscopy). The chromatographic conditions opted for the study includes Cosmosil $\mathrm{C}_{-18}$ column $(4.6 \mathrm{ID} * 250 \mathrm{~mm})$ with mobile phase consisting of methanol: phosphate buffer (pH 3.5 adjusted with orthophosphoric acid): Acetonitrile (45:35:20). Conclusion: The stability indicating method was validated as per the International Conference on Harmonization guidelines. The use of superior statistical tools for validation ensures the efficiency, quality and reproducibility of the presented method. Results obtained were agreeable and ensured the quality and reproducibility of the method.

Key words: Bisoprolol fumarate, Forced degradation study, Impurity profiling, International council for Harmonization Q3B.
\end{abstract}

\section{INTRODUCTION}

Bisoprolol fumarate (BF) approved by FDA was introduced in the year 1992 as a potent beta-blocker that selectively binds to the beta 1 receptor and competitively antagonizes the action of the adrenergic receptors. It is effectively used in the prophylaxis of angina pectoris and hypertension. ${ }^{1,2}$ Maintenance of the quality, safety and efficacy is of paramount importance for delivering a dosage form with its full potency to the patients. As we consider Bisoprolol and other drugs belonging to this category that are given as a daily dose for the sustaining of hypertension, maintaining the safety becomes much more desirable.

As stated by the International Conference on Harmonization ICH Q3B (R2) guidelines, monitoring of the identification level, reporting and qualification thresholds are of prime importance in the development of impurity profile of a drug. The differentiation should also be made in the levels of stressinduced degradation products and the process-related impurities. The qualification of these levels of impurities is needed during new drug development, drug synthesis and post-marketing surveillance. ${ }^{3,4}$
Submission Date: 15-04-2021; Revision Date: 07-10-2021; Accepted Date: 23-12-2021

DOI: 10.5530/ijper.56.1.32 Correspondence: Dr. Shiv Shankar Shukla Professor, Department of Pharmaceutical Analysis and Quality Assurance, Columbia Institute of Pharmacy, Raipur, Chhattisgarh, INDIA. E-mail:shivpharma007@ gmail.com

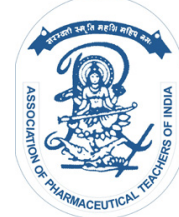

www.ijper.org 
Though the drugs are subjected to the accelerated stability studies during the process drug development but forced degradation or stress testing studies are performed as severe conditions to examine whether a degradation product is formed or not. ${ }^{5}$ As suggested by ICH and other regulatory bodies, the forced degradation studies are done by introducing the drug substances and drug products to stress conditions like oxidative, hydrolytic (which include acidic, basic and neutral hydrolysis), photolytic and thermal stress. ${ }^{6-8}$ The degradation products formed are identified by using chromatographic techniques and the structure elucidation is done by employing spectroscopic techniques. ${ }^{\text {? }}$

In recent years, two stability studies for the Bisoprolol fumarate under the stress conditions have been reported in the literature with promising outcome. For example, I. Kasagić-Vujanović et al. studied the stability-indicating method using Hydrophilic Interaction Liquid Chromatography (HILIC) ${ }^{10}$ and confirmed the formation of impurity $\mathrm{A}$ under acidic degradation. Also, kinetic studies were performed to check for their degradation behaviour. Another study was conducted by Ivana Mitrevska et al. for degradation of $\mathrm{BF}$ film-coated tablets in heat and its interaction with the diluents. The identified degradation product/impurity was concluded to be a product derived from the interaction of Bisoprolol fumarate with an excipient present that was calcium hydrogen phosphate. ${ }^{11}$

Some studies conducted on Bisoprolol fumarate corresponds to the analytical method development. To cite a few are, B. Jancic-Stojanovic et al. developed and validated a Hydrophilic Interaction Liquid chromatography (HILIC) method for determination of Bisoprolol fumarate ${ }^{12}$ and Bueno Rolim et al. developed and validated a reverse phase HPLC method $^{13}$ for the dissolution study of the Bisoprolol fumarate which was found to be accurate and precise. V.K. Morothu et al. performed the isothermal stress testing and compatibility study of Bisoprolol and few excipients were performed and an HPLC method was developed and validated for the determination of the drug and stressed compounds. ${ }^{14}$

To the best of our knowledge, the degradation products formed in the present method are novel and they have not been reported till date. A stability-indicating HPLC method for Bisoprolol fumarate was developed and the characterization of degradation products was established by Q-TOF micromass (Electronspray Ionization-Mass Spectroscopy).

\section{EXPERIMENTAL}

Pure Bisoprolol fumarate was procured from Sigma Aldrich. HPLC grade water, methanol and acetonitrile were purchased from Merck, India. The other reagents used like orthophosphoric acid, hydrochloric acid, sodium hydroxide, hydrogen peroxide were of analytical grade purchased from Merck, India.

\section{Instrumentation}

The HPLC analysis was carried out by using Younglin Acme 9000, comprised of a quaternary solvent manager and sample manager in isocratic mode along with UV Visible detector. The output and processing of the data were done through Autocome 3000 software on Windows 7 for processing of the data. All $\mathrm{pH}$ measurements were carried out using $\mathrm{pH}$ meter (Acutek) and weighing was done with Shimadzu (1 mg sensitivity).

Waters, Micromass Q-TOF micro (Separation module: Waters Alliance 2795) was used for mass measurement. Ionization was used with Electrospray positive $\mathrm{ES}^{+}$and ES, MRM unit resolution, injection volume was 20 microlitres with a flow rate of $0.4 \mathrm{~mL} / \mathrm{min}$. For mass measurement, desolvation gases used were Nitrogen and Argon at 550 liters/hour, $300^{\circ} \mathrm{C}$. Collision energy and capillary voltage was kept $4 \mathrm{ev}$ and $3000 \mathrm{~V}$ respectively.

\section{Forced Degradation Studies}

The apprehension behind the forced degradation studies is to find out the ways through which the degradation products are formed, subjecting the solid-state active pharmaceutical ingredient to the stress conditions severe to that of the accelerated stability studies. It consisted of acidic hydrolysis where $\mathrm{BF}$ was refluxed with $3 \mathrm{~N} \mathrm{HCl}$ for $48 \mathrm{hr}$. Alkaline hydrolysis was achieved by refluxing the drug with $0.1 \mathrm{~N} \mathrm{NaOH}$ for $1 \mathrm{hr}$. For neutral hydrolysis drug in its solution form was refluxed for $48 \mathrm{hr}$. Oxidative degradation study was followed by subjecting the drug to $3 \%, 15 \%$ and $30 \% \mathrm{H}_{2} \mathrm{O}_{2}$ for 7 days. Photolytic degradation was done for the drug in solution form as well as in solid-state exposing it to 1.2 million lux hours of UV light. To achieve thermal degradation, the drug in solid form was kept in an oven at $80^{\circ} \mathrm{C}$ for 7 days.

\section{Sample Preparation}

All the forced degradation studies were carried out by preparing $1 \mathrm{mg} / \mathrm{mL}$ solution of $\mathrm{BF}$ in methanol, except for acid hydrolysis where $5 \mathrm{mg}$ drug was dissolved in $5 \mathrm{~mL}$ of $3 \mathrm{~N} \mathrm{HCl}$. For base hydrolysis, $5 \mathrm{mg}$ drug was dissolved in $5 \mathrm{~mL}$ of $1 \mathrm{~N} \mathrm{NaOH}$. For oxidative degradation, $3 \mathrm{~mL}$ of $\mathrm{H}_{2} \mathrm{O}_{2}$ was added to the drug in its solution form. Each stock solution prepared was 
further diluted to the concentration of $100 \mu \mathrm{g} / \mathrm{mL}$ with methanol. Before each HPLC analysis, the solution was filtered through Whatman filter paper grade $602 \mathrm{~h}$ and sonicated in a bath sonicator for $15 \mathrm{~min}$.

\section{Chromatographic Conditions}

The method was found to be accurate and precise by using Cosmosil $\mathrm{C}_{18}$ PAQ column $(4.6 \mathrm{ID} * 250 \mathrm{~mm})$ and mobile phase which consisted of methanol: phosphate buffer (pH 3.5 adjusted with orthophosphoric acid): acetonitrile in the ratio 45:35:20 in the isocratic mode. Flow rate of was $1.2 \mathrm{~mL} / \mathrm{min}$ was maintaied throughout the analysis. The detection wavelength used was $220 \mathrm{~nm}$ and injection volume used was $1 \mu$ l. The column temperature was maintained at $25^{\circ} \mathrm{C}$.

\section{RESULTS AND DISCUSSION}

\section{Optimization of Chromatographic Conditions}

To develop an accurate, precise, reliable method of the proper separation of $\mathrm{BF}$ and its degradants several mobile phase compositions were experimented at different $\mathrm{pH}$, flow rate, column and other dependent variables have experimented. Several mobile phase compositions were designed by altering the concentration of methanol, acetonitrile and phosphate buffer. The series of $\mathrm{pH}$ ranging from 2 to 5 was wandered during the course of study. Due to the polar nature of the drug the outstanding results were achieved by using a composition of methanol, buffer and acetonitrile in the ratio of 45:35:20.

\section{Degradation Behavior of Bisoprolol Fumarate}

A comprehensive study for the stress-induced degradation of $\mathrm{BF}$ was examined using HPLC-UV detector.

\section{Hydrolytic Degradation}

During the base and neutral hydrolysis, sufficient stability was found for the drug and no degradation products were formed (Figure S1). The acidic degradation study revealed that the degradants formed were already identified in the previously cited literratures.

\section{Oxidative Degradation}

The oxidative degradation study demonstrated that no degradants where formed when methanol was employed as diluents for the preparation of stock solution inspite of the nature of the drug which suggests its susceptibility towards oxidation. The same has been confirmed in various literatures. For this reason, authors conducted the studies in a varied manner to confirm the oxidative degradation. Oxidative degradations were performed in aqueous solution form of the drug by adding 15\% hydrogen peroxide as stressor and $1 \mathrm{~mL}$ of tertiary butyl hydrogen peroxide (TBHP). Observed degradation product's peak in the HPLC chromatogram did not reveal any degradation (Figure S2 and S3).

\section{Photolytic Degradation}

The drug in solution, as well as solid-state form, was exposed to 1.2 million lux hours of UV light and no degradation was observed (Figure S4).

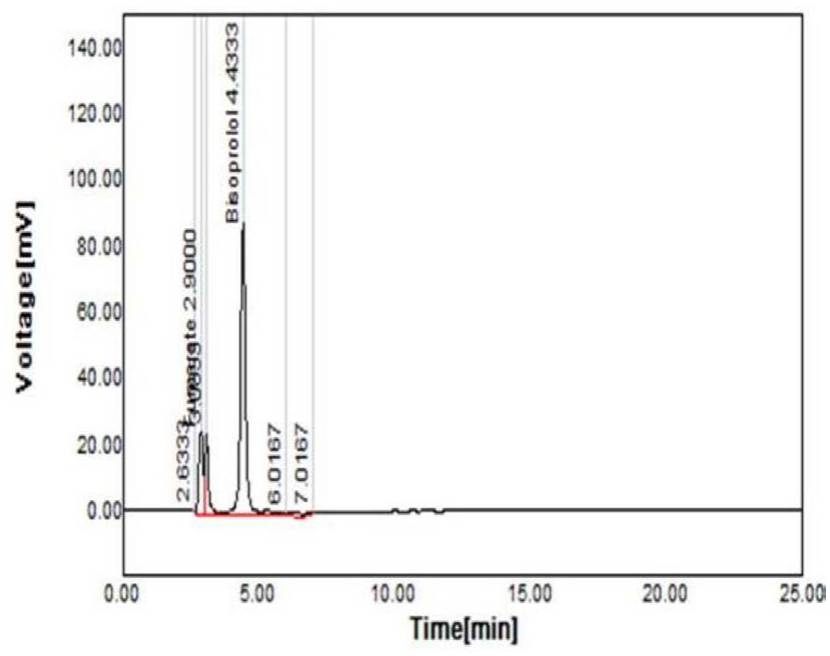

Figure S1: HPLC chromatogram of Basic Hydrolytic Degradation $(3 \mathrm{~N} \mathrm{NaOH})$ of Bisoprolol fumarate.

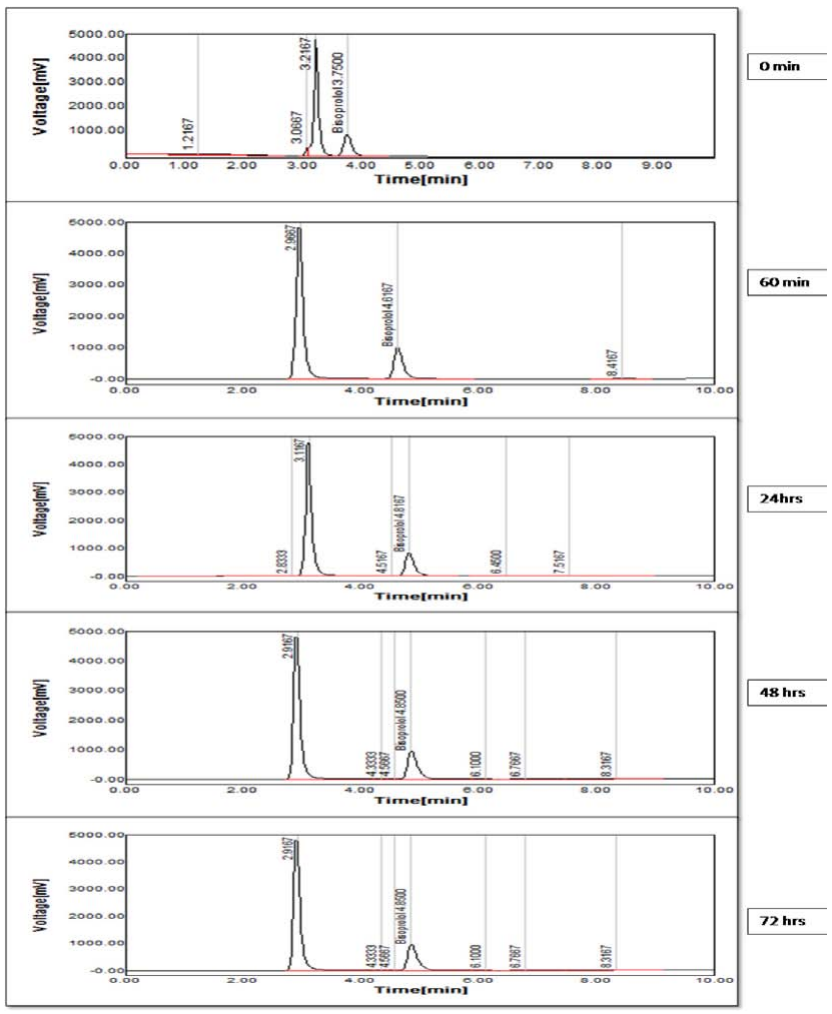

Figure S2: HPLC chromatogram of Oxidative Degradation (15\% $\mathrm{H}_{2} \mathrm{O}_{2}$ ) of Bisoprolol Fumarate for $72 \mathrm{hr}$. 


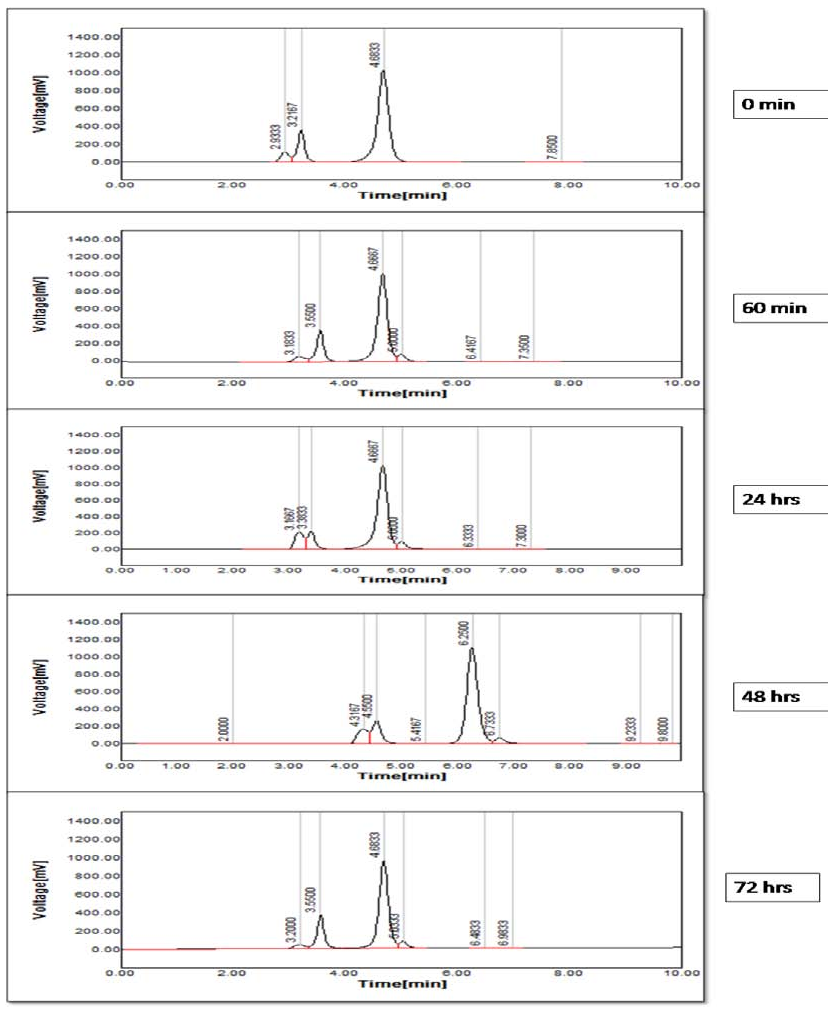

Figure S3: HPLC chromatogram of Oxidative Degradation (TbHP) of Bisoprolol Fumarate for $72 \mathrm{hr}$.

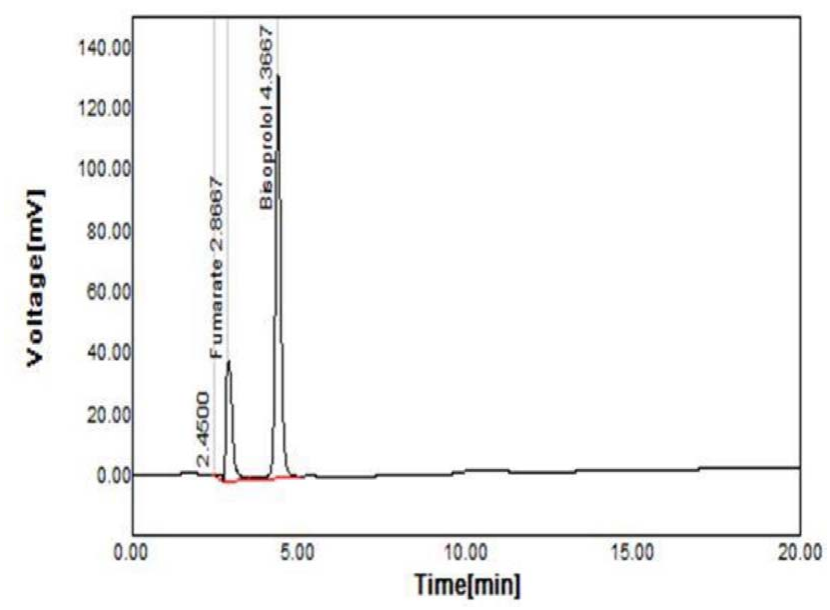

Figure S4: HPLC chromatogram of Photolytic Degradation (1.2 million lux hours) of Bisoprolol Fumarate for 7 days.

\section{Thermal Degradation}

By keeping the drug at $80^{\circ} \mathrm{C}$ for 7 days, it was observed that the drug did not withstand its stability and HPLC chromatogram revealed the formation of a degradation product was observed at retention time $6.00 \mathrm{~min}$ (Figure 1). For analyzing the degradation product, the test compound was subjected to Q-TOF Micromass ESI-MS/MS (Figure 2). The proposed fragmentation pattern of the test compound in order to determine the

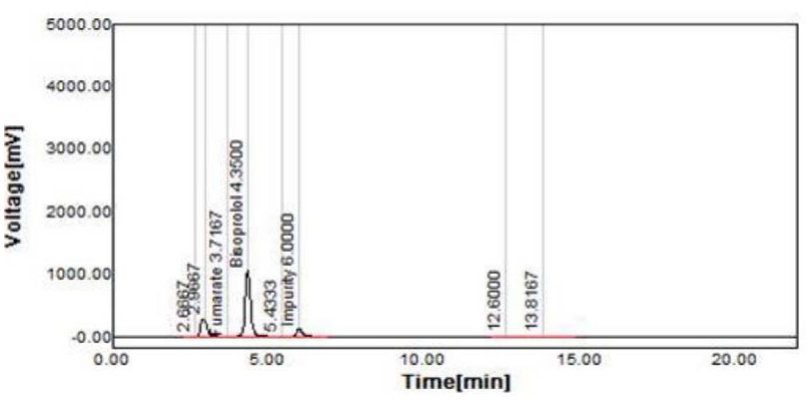

Figure 1: HPLC chromatogram of Thermal Degradation $\left(80^{\circ} \mathrm{C}\right)$ of Bisoprolol Fumarate for 7 days.

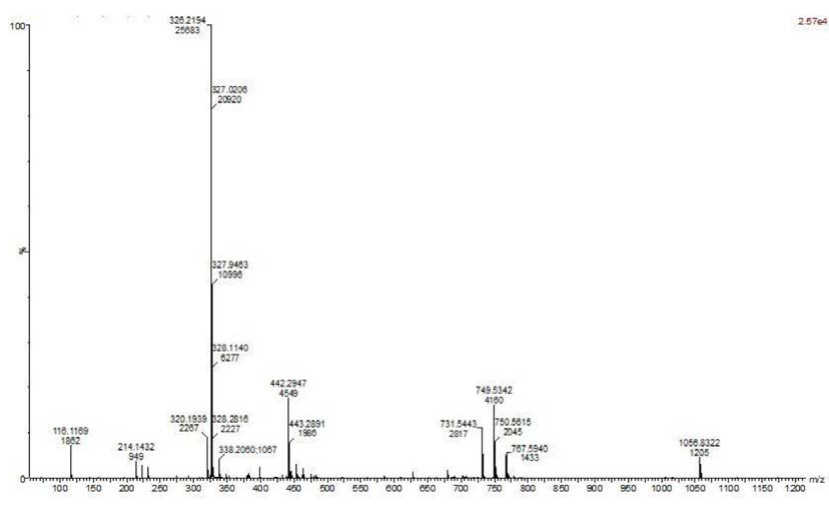

Figure 2: ESI/MS/MS Spectrum of Bisoprolol ( $\mathrm{m} / \mathrm{z} 326)$, fumaric acid ( $\mathrm{m} / \mathrm{z} 116)$, impurity IA (m/z749), fragmentation ion IF $(\mathrm{m} / \mathrm{z}$ 731).

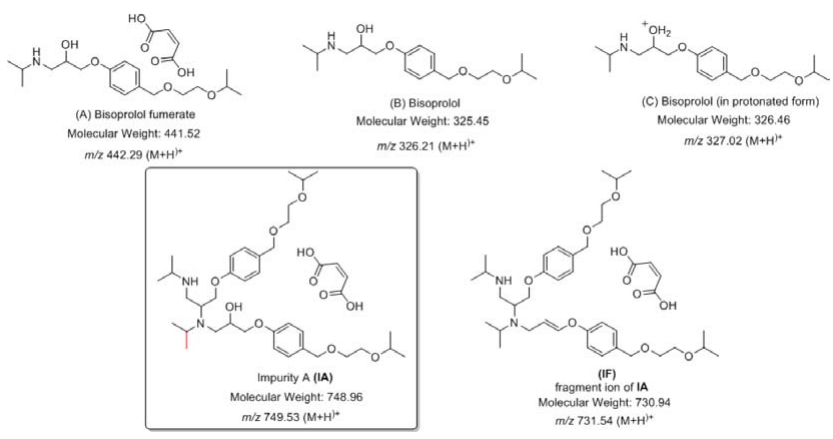

Figure 3: Proposed structures of protonated degradation products of Bisoprolol Fumarate.

formation of expected degradants in the presence of heat has been depicted with the elemental composition and molecular mass in Figure 3.

Q-TOF Micromass ESI-MS/MS study of Bisoprolol Fumarate and its degradants and Projected mechanism for the formation of the degradation product

From the HPLC chromatogram as shown in Figure 1, three different peaks correspond to fumaric acid, bisoprolol, unknown impurities were observed at RT $2.966 \mathrm{~min}, 4.35 \mathrm{~min}$ and $6.00 \mathrm{~min}$, respectively. To 
investigate about the possible structure of unknown impurity, the mass spectrum of degradant was studied based on the $m / z$ values of their $[\mathrm{M}+\mathrm{H}]^{+}$ions. As shown in Figure 2, the $m / z$ at 326 and 116 displayed the presence of bisoprolol and fumaric acid, whereas the appearance of $\mathrm{m} / \mathrm{z}$ at 442 validated the existence of bisoprolol fumarate. Furthermore, an increase in the mass of molecular ion by $01 \mathrm{AMU}(\mathrm{m} / ₹ 327)$ may be attributed to the protonated form of bisoprolol under stress conditions.

Based on the molecular ion peak observed at $\mathrm{m} / \mathrm{z}$ 749 in MS/MS of degradant, mass higher than 307 $\mathrm{Da}$ of bisoprolol fumarate is expected to be found impurity after thermal degradation, as shown in HPLC chromatogram at RT $6.00 \mathrm{~min}$. The anticipated structure of impurity (IA) based on MS/MS with $m / z 749$ has been shown in Figure 3. We therefore, believe that the formation of impurity (IA) is possible during the stress condition via intramolecular nucleophilic substitution reaction of bisoprolol fumarate as depicted in Figure 3. We also observed the $m / z$ at $731 \mathrm{amu}$, which is expected to be the fragmentation ion (IF) of target impurity (IA). The difference in the mass of $18 \mathrm{Da}$ between IA and IB clearly suggested the formation of IF via elimination reaction/dehydration of target impurity IA (Figure 4).

\section{Method Validation}

Stability indicating HPLC method was developed and validated as per the ICH Q2 (R1) guidelines. The method was found to be accurate and precise.

\section{Specificity}

The stressed samples of $\mathrm{BF}$ were analyzed for the specificity of the proposed stability-indicating method to ensure capability of the method to separate the degradation products from the pure bulk drug BF. The specificity of the method was established by determining the resolution factor and peak purity of stressed samples of BF. Assay of the Pure BF was determined against the stress BF samples. The determined peak purity shows the undoubted specificity of the method.

\section{Linearity and Range}

For the determination of linearity, $\mathrm{BF}$ samples in the range of $20-100 \mu \mathrm{g} / \mathrm{mL}$ were analyzed and the correlation coefficient was found to be 0.999 (Figure 5). The range analyzed was used for 6 concentrations and consecutively three days in the same range. All the data obtained satisfies the criteria required to have a linear relationship between the dependent and independent variable (Table 1). Residual plots for individual drug show a random distribution of data points around the regression line indicates a good linear relationship (Figure 5).
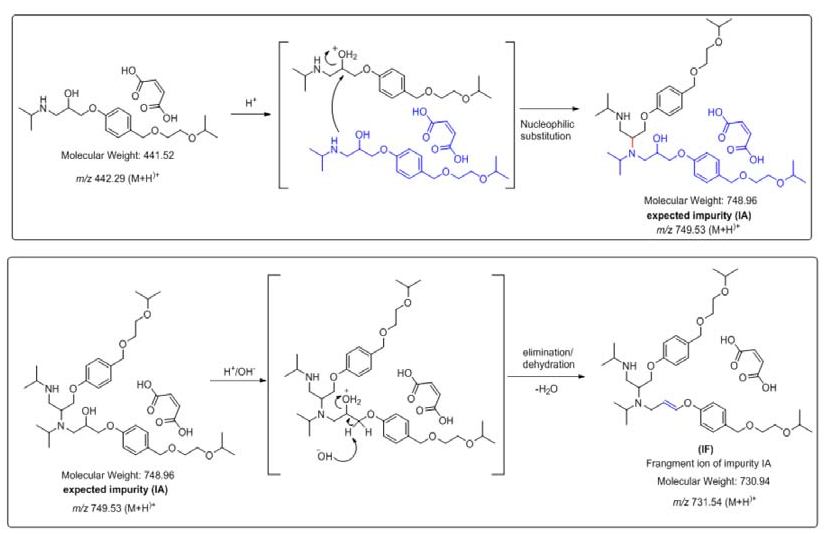

Figure 4: Proposed fragmentation pathway of protonated Bisoprolol Fumarate.

\begin{tabular}{|c|c|c|c|c|}
\hline \multicolumn{2}{|c|}{ Parameters } & Unknown & Criterion & Comment \\
\hline \multirow{5}{*}{$\begin{array}{l}\text { Regression } \\
\text { statistics }\end{array}$} & Multiple R & 0.999 & \multirow{5}{*}{$\begin{array}{l}\text { Smaller value indicates good } \\
\text { fit }\end{array}$} & \\
\hline & R Square & 0.999 & & \\
\hline & Adjusted R Square & 0.999 & & \\
\hline & Standard error & 96.83 & & \\
\hline & Total observations & 5 & & \\
\hline \multirow[t]{6}{*}{ ANOVA } & $\begin{array}{c}F \text { value } \\
\text { (Conc. Variable) }\end{array}$ & 4086.353 & $F$ value $>F$ Critical & F Critical $=10.12$ \\
\hline & $\begin{array}{l}\text { F Significance } \\
\text { (Conc. Variable) }\end{array}$ & 8.43E-06 & $F$ significance $<\alpha$ & Alpha $=0.05$ \\
\hline & $\begin{array}{c}\text { T Stat } \\
\text { (Conc. Variable) }\end{array}$ & 63.924 & $\begin{array}{l}\text { Should not lie between } \pm \mathrm{T} \\
\text { Critical }(-2.77 \text { to }+2.77)\end{array}$ & $\mathrm{T}$ Critical $=2.77$ \\
\hline & $\begin{array}{c}\text { P-value } \\
\text { (Conc. Variable) }\end{array}$ & 8.43E-06 & $P$ value $<\alpha$ & \\
\hline & $\begin{array}{l}\text { Lower 95\% - Upper 95\% } \\
\text { (Conc. Variable) }\end{array}$ & 93.005- 102.75 & $\begin{array}{l}\text { Zero should not lie between } \\
\text { upper and lower } 95 \% \text { interval }\end{array}$ & \\
\hline & $\begin{array}{c}\text { The standard error of } \\
\text { Y-intercept }\end{array}$ & 101.565 & $\begin{array}{c}\text { Used for Standard deviation } \\
\text { calculation. }\end{array}$ & \\
\hline
\end{tabular}




\section{Robustness}

For estimating how robust the method is, some small and purposeful variations were done in the flow rate, column temperature, and mobile phase. Flow rate was changed by $0.2 \mathrm{~mL} / \mathrm{min}$ (i.e. $0.8 \mathrm{~mL} / \mathrm{min}$ to $1.2 \mathrm{~mL} / \mathrm{min}$ ) that show $\%$ RSD of $0.78 \%$. The column temperature was varied by $5^{\circ} \mathrm{C}$ (i.e. 25 to $30^{\circ} \mathrm{C}$ ) and the $\%$ RSD found was $1.23 \%$. Similarly when the mobile phase was altered by changing the $\mathrm{pH}$ from 3.5-4.5 the \%RSD found

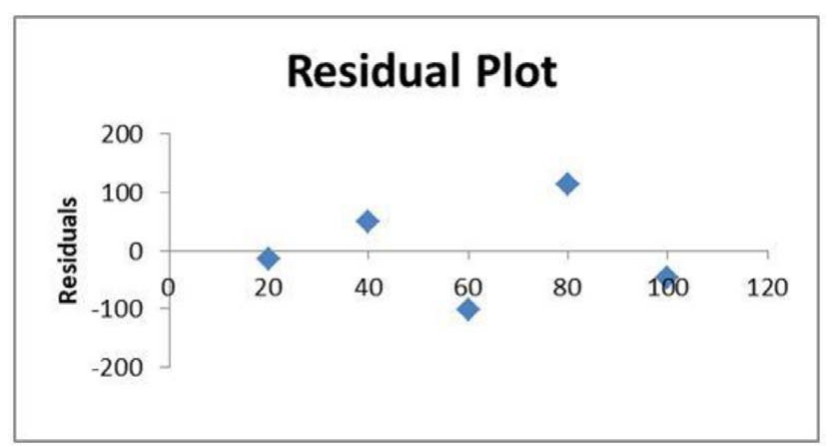

Figure 5: Residual plot in the observed range $(20-100 \mu \mathrm{g} / \mathrm{ml})$. was $1.45 \%$. All the above-stated robustness parameters qualified the guidelines demonstrating that the method is robust enough.

\section{Accuracy}

According to the British Pharmacopoeia the accuracy study was carried out in the levels of $50 \%, 100 \%$ and $150 \%$. The concentrations chosen $(20,40$ and $60 \mu \mathrm{g} / \mathrm{mL})$, were evaluated in triplicate. The $\%$ recovery was calculated and was found in the range of 99.81-102.22 $\%$ (Table 2).

\section{Precision}

Inter and intraday precisions were performed by analyzing the samples on the same day in triplicate and in successive for 3 days. Determining the peak area in the concentrations chosen 20,40 , and $60 \mu \mathrm{g} / \mathrm{mL}$ depicted that the method is precise. The value of $\mathrm{p}$ found greater than the significance level and $F$ Value were smaller than F-Critical value. It indicates excellent reproducibility of the method. The results are denoted in Table 3 and 4 .

\begin{tabular}{|c|c|c|c|c|c|c|}
\hline \multicolumn{7}{|c|}{ Table 2: Inter day precision (Data analysis through Anova Single factor). } \\
\hline Summary & Count & Sum & Average & Variance & \\
\hline Groups & 3 & 119.9 & 39.96667 & 411.3265 & & \\
\hline A & 3 & 120.5 & 40.16667 & 413.5385 & & \\
\hline B & 3 & 120.55 & 40.18333 & 394.1858 & & \\
\hline C & 3 & 120.41 & 40.13667 & 404.333 & & \\
\hline D & & & & & & \\
\hline ANOVA & SS & df & MS & F & P-value & F crit \\
\hline Source of Variation & 0.0894 & 3 & 0.0298 & $7.34 \mathrm{E}-05$ & 0.999999 & 4.066181 \\
\hline Between Groups & 3246.768 & 8 & 405.846 & & & \\
\hline Within Groups & 3246.857 & 11 & & & & \\
\hline Total & & & & & \\
\hline
\end{tabular}

\begin{tabular}{|c|c|c|c|c|c|c|}
\hline \multicolumn{2}{|c|}{ Summary } & \multirow[b]{2}{*}{ Sum } & \multirow[b]{2}{*}{ Average } & \multirow[b]{2}{*}{ Variance } & & \\
\hline Groups & Count & & & & & \\
\hline & 3 & 120.58 & 40.19333 & 419.2266 & & \\
\hline & 3 & 120.93 & 40.31 & 396.6433 & & \\
\hline & 3 & 120.65 & 40.21667 & 384.2433 & & \\
\hline & 3 & 120.72 & 40.24 & 399.8721 & & \\
\hline ANOVA & & & & & & \\
\hline Source of Variation & sS & df & MS & $\mathbf{F}$ & P-value & F crit \\
\hline Between Groups & 0.022867 & 3 & 0.007622 & 1.91E-05 & 1 & 4.066181 \\
\hline Within Groups & 3199.971 & 8 & 399.9963 & & & \\
\hline Total & 3199.994 & 11 & & & & \\
\hline
\end{tabular}




\begin{tabular}{|c|c|c|}
\hline \multicolumn{3}{|c|}{ Table 4: Recovery Data. } \\
\hline $\begin{array}{c}\text { Amount } \\
\text { Added }\end{array}$ & $\begin{array}{c}\text { Accuracy/Calculated } \\
\text { Spiked concentration }\end{array}$ & Recovery \\
\hline$(\boldsymbol{\mu g} / \mathrm{ml})$ & $(\boldsymbol{\mu g} / \mathrm{ml}) \pm$ SD; RSD & $(\%)$ \\
\hline 20 & $20.16 \pm 0.34 ; 1.68$ & 100.8 \\
\hline 40 & $40.89 \pm 0.40 ; 0.98$ & 102.25 \\
\hline 60 & $59.89 \pm 0.33 ; 0.55$ & 99.81 \\
\hline
\end{tabular}

\section{CONCLUSION}

The degradation studies induced on Bisoprolol fumarate were as per the $\mathrm{ICH}$ guideline (hydrolytic, photolytic, thermal and oxidative stress). These studies revealed the formation of one degradation product and one fragmented product of the degradant during the thermal stress due the interaction of the drug product with heat which induced a nucleophilic substitution reaction. The degradation behaviour was justified through the plausible mechanism by which the degradation products were formed. The degrdation products formed were identified for their mass by ESIQTOF-Mass Spectroscopy.

In the present paper, we have applied newer strategies for validation of the developed method that concurrently satisfies the concept of Quality by Design (QbD). General parameter of validation of method depends on linearity, standard deviation and standard error. the coefficient of determination is a common method fro the verification of linearity and its taken that is $R^{2}$ value approaches closely to 1 then there is a linear relationship, but the same not suggested in the literatures. ${ }^{15}$ To rationalize the same we have opted for regression analysis and residual analysis for validating the linear relationship between the dependent and independent variable for clear understanding and better interpretation of the results obtained. One way ANOVA is used for the precision study which is more apparent and acceptable approach as compared to Relative standard deviation. Further, a HPLC method was developed and validated that can be used in the determination of stability studies and routine qualitative analysis.

\section{ACKNOWLEDGEMENT}

The authors are thankful to the Columbia Institute of Pharmacy for providing the vital facilities for carrying out the research work. The authors are also grateful to the Department of Science and Technology (DSTFIST) Letter no-SR/FST/COLLEGE/2018/418, New Delhi for providing the financial assistance.

\section{CONFLICT OF INTEREST}

The authors declare no conflict of interest.

\section{ABBREVIATIONS}

ICH: International Council for Harmonization; API: Active pharmaceutical ingredient; BF: bisoprolol fumarate; RSD: Relative standard deviation; SIM: Stability indicating method; RT: Retention Time; AMU: Atomic Mass unit; ESI-QTOF: Electronspray Ionization- Quadrapole Time of Flight; Nm: namometer; $\mathbf{m g} / \mathbf{m L}$ : milligram per milliliter; $\mathbf{H}$ : hours.

\section{REFERENCES}

1. De Hoon JNJM, Vanmolkot FHM, Van De Ven LLM, Van Bortel LMAB. Quality of life comparison between bisoprolol and nifedipine retard in hypertension. Cardiovasc Drugs Ther. 1997;11(3):465-71. doi: 10.1023/a:1007701606758, PMID 9310275.

2. Marazzi G, Campolongo G, Pelliccia F, Quattrino S, Cacciotti L, Miano M, et al. Bisoprolol better than atenolol as add on therapy to ACE inhibitors in blood pressure control. J Hypertens. 2018;36(Supplement 1):e43. doi: 10.1097/01.hjh.0000539074.54110.f7.

3. Patel PN, Borkar RM, Kalariya PD, Gangwal RP, Sangamwar AT, Samanthula G, Ragampeta S. Characterization of degradation products of ivabradine by LC-HR-MS/MS: A typical case of exhibition of different degradation behaviour in $\mathrm{HCl}$ and $\mathrm{H} 2 \mathrm{SO} 4$ acid hydrolysis. J Mass Spectrom. 2015;50(2):344-53. doi: 10.1002/jms.3533, PMID 25800016.

4. Patel PN, Kalariya PD, Gananadhamu S, Srinivas R. Forced degradation of fingolimod: Effect of co-solvent and characterization of degradation products by UHPLC-Q-TOF-MS/MS and 1H NMR. J Pharm Biomed Anal. 2015;115:388-94. doi: 10.1016/j.jpba.2015.07.028, PMID 26279369.

5. Singh S, Handa T, Narayanam M, Sahu A, Junwal M, Shah RP. A critical review on the use of modern sophisticated hyphenated tools in the characterization of impurities and degradation products. J Pharm Biomed Anal. 2012;69:148-73. doi: 10.1016/j.jpba.2012.03.044, PMID 22521633.

6. EMA. Stability. Guideline on Stability Testing: stability Testing of existing Active Substances. Regul EMA; 2004.

7. ICH Expert Working Group. ICH guideline. In: International Conference on Harmonization. Vol. Q1A(R2) Stability Testing of New Drug Substances and Products; 2003.

8. WHO. Stability testing of active pharmaceutical ingredients and finished pharmaceutical products. World Health Organization Technical Report Series. Vol. 953 [annex] 2 [World Health Organ Tech rep ser. p. 2009].

9. Maggio RM, Vignaduzzo SE, Kaufman TS. Practical and regulatory considerations for stability-indicating methods for the assay of bulk drugs and drug formulations. TrAC Trends Anal Chem. 2013;49:57-70. doi: 10.1016/j. trac.2013.05.008.

10. Kasagić-Vujanović I, Stojanović BJ, Ivanović D. Monitoring of bisoprolol fumarate stability under different stress conditions. IFMBE Proc. 2017:415-24. doi: 10.1007/978-981-10-4166-2_64.

11. Mitrevska I, Kikovska-Stojanovska E, Petrusevski G, Chachorovska M, Memed-Sejfulah S, Ugarkovic S. Identification and structural characterization of unidentified impurity in bisoprolol film-coated tablets. Advances in Chemistry. 2017;2017:1-16. doi: 10.1155/2017/3047517.

12. Kasagić-Vujanović I, Jančić-Stojanović B, Rakić T, Ivanović D. Design of experiments in optimization and validation of a hydrophilic interaction liquid chromatography method for determination of amlodipine besylate and bisoprolol fumarate. J Liq Chromatogr Relat Technol. 2015;38(8):919-28. doi: 10.1080/10826076.2014.991872.

13. Rolim CMB, Brum L, Fronza M, Malesuik MD, Bajerski L, Dalmora SL. Development and validation of an RP-HPLC method for the dissolution 
studies of bisoprolol in pharmaceutical dosage forms. J Liq Chromatogr Relat Technol. 2005;28(3):477-86. doi: 10.1081/JLC-200044531.

14.

Marothu VK, Yerramothu P, Gorrepati M, Majeti S, Mamidala SK, Nellutla A. Application of HPLC to assess the compatibility of bisoprolol fumarate with selected excipients in mixtures by isothermal stress testing. Ann Pharm Fr. 2015;73(6):442-51. doi: 10.1016/j.pharma.2015.05.001, PMID 26142745.

15. Prichard L, Barwick V. Preparation of calibration curves: A guide to best practice. LGC Group, Ltd TR LGC/VAM/2003/032. Teddington, Middlesex, UK.

\section{PICTORIAL ABSTRACT}

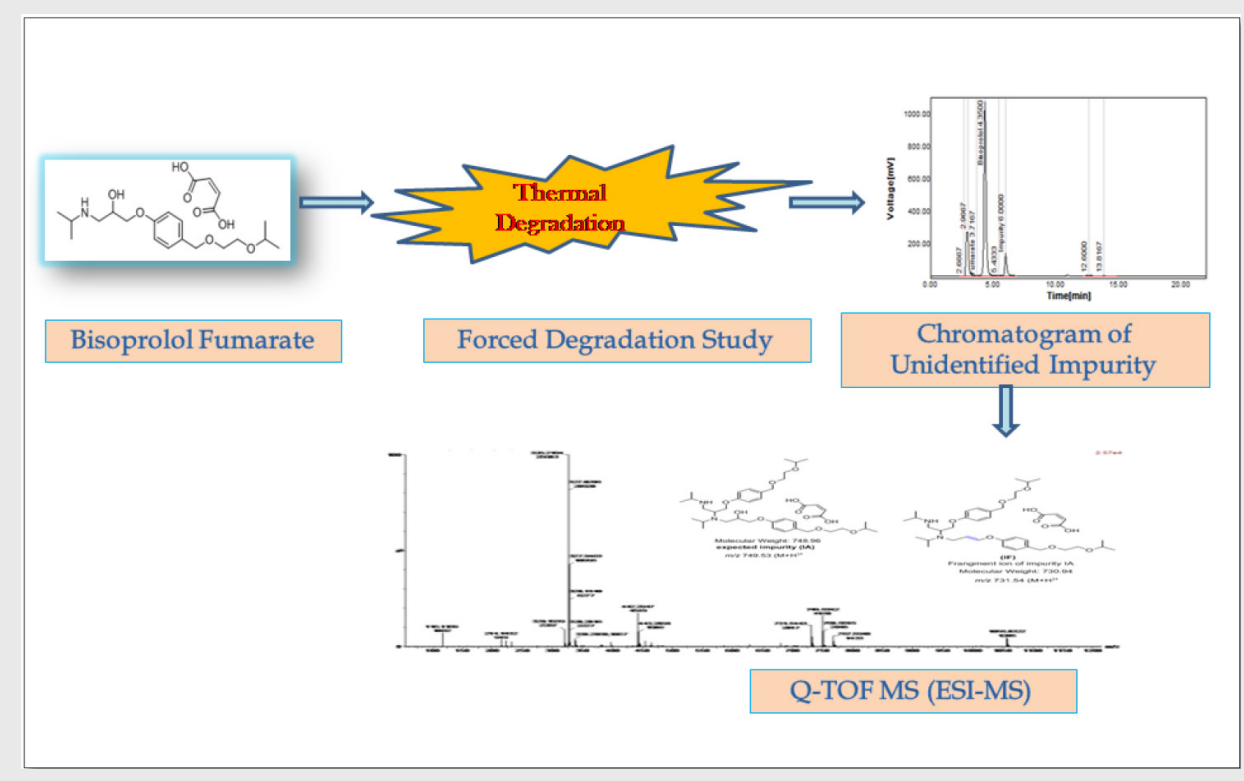

\section{SUMMARY}

The degradation studies induced on Bisoprolol fumarate were as per the ICH guideline (hydrolytic, photolytic, thermal and oxidative stress). These studies revealed the formation of one degradation product and one fragmented product of the degradant during the thermal stress due the interaction of the drug product with heat which induced a nucleophilic substitution reaction. The degradation behaviour was justified through the plausible mechanism by which the degradation products were formed. The degrdation products formed were identified for their mass by ESI-QTOF-Mass Spectroscopy. In the present paper, we have applied newer strategies for validation of the developed method that concurrently satisfies the concept of Quality by Design (QbD). General parameter of validation of method depends on linearity, standard deviation and standard error. The coefficient of determination is a common method for the verification of linearity and it's taken that is $R^{2}$ value approaches closely to 1 then there is a linear relationship, but the same not suggested in the literatures. The major findings in the presented work are the degradation products formed in the course of thermal degradation. The complete thermal degradation products were identified by HPLC, Q-TOF micromass (ESI-MS). The developed HPLC method was validated as per the ICH guidelines. The use of superior statistical tools for validation ensures the efficiency, quality and reproducibility of the presented method. Results obtained were agreeable and ensured the quality and reproducibility of the method. To rationalize the same we have opted for regression analysis and residual analysis for validating the linear relationship between the dependent and independent variable for clear understanding and better interpretation of the results obtained. One way ANOVA is used for the precision study which is more apparent and acceptable approach as compared to Relative standard deviation. Further, a HPLC method was developed and validated that can be used in the determination of stability studies and routine qualitative analysis. 


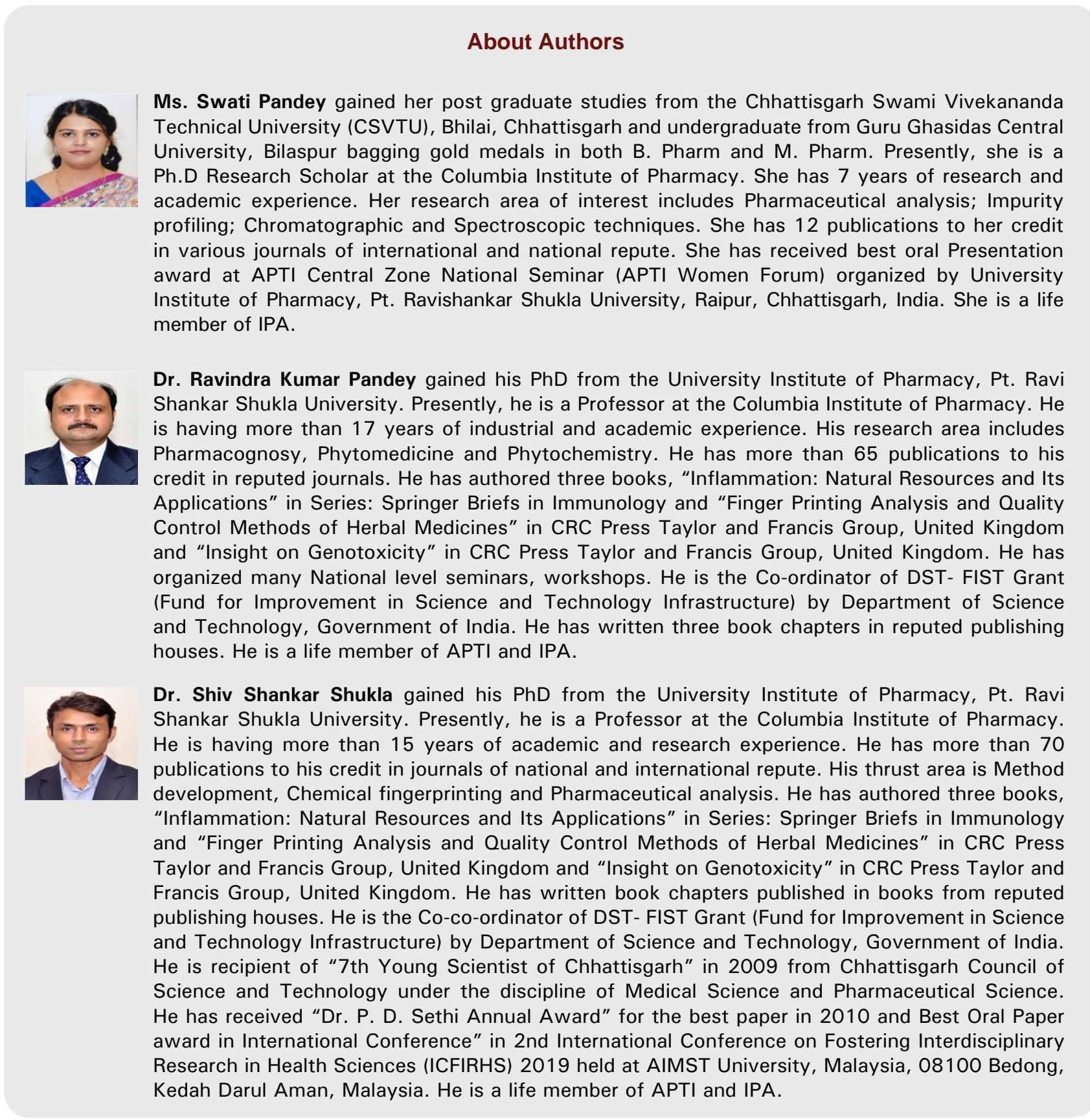

Cite this article: Pandey S, Pandey R, Shukla SS. Spectroscopic Substantiation for the Identification of Degradants by Q-TOF Micromass (ESI-MS) in Bisoprolol Fumarate with an Inventive Validation Approach for Stability Indicating HPLC Method. Indian J of Pharmaceutical Education and Research. 2022;56(1):272-80. 